\title{
Clinical improvement in a patient with monostotic melorheostosis after treatment with denosumab: a case report
}

\author{
Sarah Byberg ${ }^{1}$, Bo Abrahamsen², Moustapha Kassem³ ${ }^{3}$ Stuart Ralston ${ }^{4}$ and Peter Schwarz ${ }^{1 *}$ (D
}

\begin{abstract}
Background: A 20-year-old Danish woman with melorheostosis in her right femoral shaft and disabling pain in the affected area, whose symptoms did not in the long term respond to zoledronic acid, experienced continuous remission of pain after treatment with denosumab. To the best of our knowledge, this is the first case report on denosumab treatment for melorheostosis.
\end{abstract}

Case presentation: Radiologic findings and bone biopsy showed irregular cortical hyperostosis in the right femoral shaft with increased tracer uptake on $\mathrm{Tc}^{99}$-bone scan.

The diagnosis of melorheostosis was made based on the radiological findings. There was a good initial response to zoledronic acid administration, but after relapse of pain, the second and third administrations had a poor effect. As a second line of treatment denosumab was administered at 8-week intervals, the frequency was based on our patient's symptoms and on biochemical markers of bone turnover.

Conclusion: This is the first report indicating that denosumab has a place in the treatment of melorheostosis when the effect of bisphosphonate treatment is insufficient.

Keywords: Melorheostosis, Denosumab, Case report

\section{Background}

Melorheostosis is a rare, nonhereditary sclerosing bone dysplasia first described in 1922 by Leri and Joanny [1]. The minimal prevalence has been estimated to be 0.9 per million [2]. Establishing the diagnosis melorheostosis is challenging. It is primarily based on radiological findings as defined by Freyschmidt [3] and on the exclusion of other sclerosing bone diseases. It is a chronic progressive disorder and affects females and males equally [3] with no known curative treatment $[4,5]$. Case reports have documented pain relief by treatment with bisphosphonates [6-11].

This is the first report describing the treatment of melorheostosis with denosumab. Denosumab was introduced as a second line of treatment, after insufficient effect of zoledronic acid. Treatment with denosumab has shown remarkable clinical effect.

\footnotetext{
* Correspondence: peter.schwarz@regionh.dk

${ }^{1}$ Department of Endocrinology, Copenhagen University Hospital

Rigshospitalet, Blegdamsvej 9, 2100 Copenhagen, Denmark

Full list of author information is available at the end of the article
}

\section{Case presentation}

A 20-year-old Danish woman was referred with constant pain in the right proximal thigh that had progressed for 8 years. She had no other known medical conditions. Menarche was at age 13. There was no family history of sclerosing bone diseases. The limb pain was aggravated at night and was moderately relieved during physical activity and by cold baths. She was on daily analgesic medication with nonsteroidal anti-inflammatory drugs, paracetamol, and weak opioid agonists, and she was on sick leave from her university studies at the time of referral due to her symptoms. She was using shoe inserts because of leg length discrepancy.

At age 11 she had consulted a rheumatologist because of hip joint pain. Guided by ultrasound a hip joint puncture was performed due to fluid gathering; serology was negative. After the puncture, the joint pain ceased.

Six months prior to referral to our clinic, she was involved in a traffic accident and hit by a car from the right at knee level. She was discharged from an emergency room (ER) with no suspected fracture and a

(C) The Author(s). 2018 Open Access This article is distributed under the terms of the Creative Commons Attribution 4.0 International License (http://creativecommons.org/licenses/by/4.0/), which permits unrestricted use, distribution, and 
radiological examination was not performed. She reported that there was significant worsening of the femoral pain after the traffic accident.

\section{Clinical findings}

A clinical examination revealed no skin lesions, café au lait spots, or redness; there was no increased temperature or swelling in her right thigh. Leg length was unequal but within normality.

\section{Diagnostic assessment}

She was instructed to fill out a diary with daily registration of pain on an analog scale from zero to 10 , where increasing values were equivalent to more intensive pain. Orally administered analgesics were required when the pain exceeded a score of 6 or more, and the score 10 was reserved for symptoms that kept our patient from falling asleep and that did not respond adequately to orally administered analgesics.

Magnetic resonance (MR) and positron emission tomography-computed tomography (PET-CT) scans revealed significant increased cortical thickness in the right femoral diaphysis that partially obliterated the medullary cavity (Fig. 1). The surface of the sclerotic bone was uneven. A Tc ${ }^{99}$-bone scan showed a pathological increase in uptake in most of the right femoral shaft (Fig. 2).

Biochemical bone markers were normal, including normal alkaline phosphatase.

Screening for the GNAS1 activating mutation R201 was negative in peripheral blood; as was mutation screening of the SQSTM1 gene, which has been reported to be mutated in Paget's disease of bone.

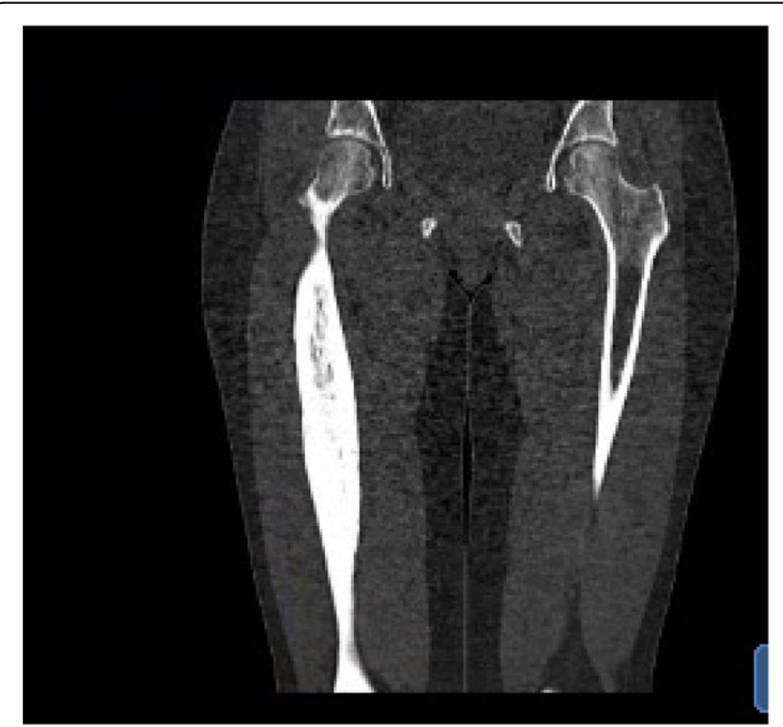

Fig. 1 Computed tomography of right femoral shaft. Computed tomography scan showing cortical thickening of the patien's right femoral shaft

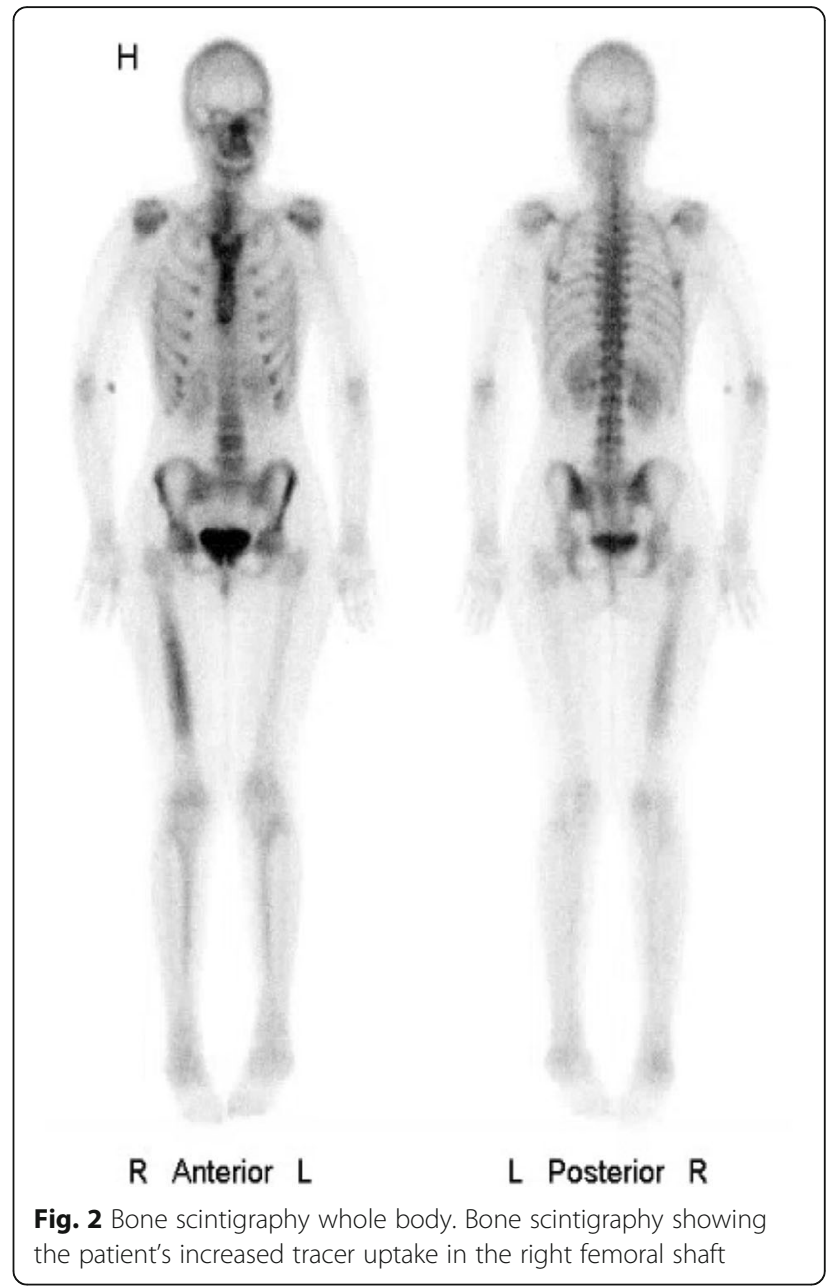

A bone biopsy was performed and showed thickened bone springs with preserved lamellar structure and slightly accentuated cement lines. There was no fibrosis, inflammation, or increased alcian positivity, which would be suggestive of active osteomyelitis. There were no signs of malignancy or neoplasia.

A gynecological examination prior to referral had found a mild degree of polycystic ovaries (PCO) with normal androgen status. There were no endocrinopathies.

\section{Diagnostic reasoning and differential diagnosis}

During the clinical investigation, four tentative diagnoses were raised: atypical fibrous dysplasia, Paget's disease of bone, chronic non-infectious osteomyelitis, and melorheostosis. The young age of our patient, normal alkaline phosphatase, and sparing of the metaphysis of the affected bone made Paget's disease of bone highly unlikely.

The cortical thickening is atypical for the diagnosis of fibrous dysplasia. The absence of café au lait spots, the normal age at menarche, the absence of other endocrine disorders, and the negative GNAS1 mutation examination weighed against a diagnosis of fibrous dysplasia. The long 
bones are a common location for chronic non-infectious osteomyelitis and this can present in childhood; however, the radiological appearance and bone histology did not provide support for this differential diagnosis. With special emphasis on the uneven surface of the affected bone on $\mathrm{X}$-ray (Fig. 3), the diagnosis of melorheostosis, which was fully compatible with the relatively unremarkable histology, was found to be the most plausible diagnosis. In addition, the normal bone chemistry is in keeping with melorheostosis [5] although in polyostotic cases alkaline phosphatase can be increased [11].

\section{Therapeutic intervention}

The timeline for intervention and clinical outcome is presented in Fig. 4. Initially, zoledronic acid $5 \mathrm{mg}$ was administered intravenously three times with 10 -month and 12-month intervals; our patient had pain relief after the first administration, but a poor effect of the second and third injection. Using an analog pain scale she reported average pain of 9 prior to treatment, 6 after treatment with zoledronic acid, and 4 from 2 to 10 months after initiation of treatment with denosumab. Looking at the usage of pain medication, it went from daily dosage before treatment to $23 \%$ of days after treatment with zoledronic acid, and to no orally administered analgesics for 8 months following treatment with denosumab.

In October 2015, denosumab was chosen as the second line of treatment based on the hypothesis that the pain was caused by increased bone turnover. A dose of $60 \mathrm{mg}$ was injected subcutaneously with some remission of pain that lasted for 6 weeks. At the same time as the pain relapsed, there was an increase in alkaline phosphatase, PINP, CTx, and osteocalcin in blood tests. Biochemistry before and during treatment is listed in Table 1. Based on these findings it was decided to

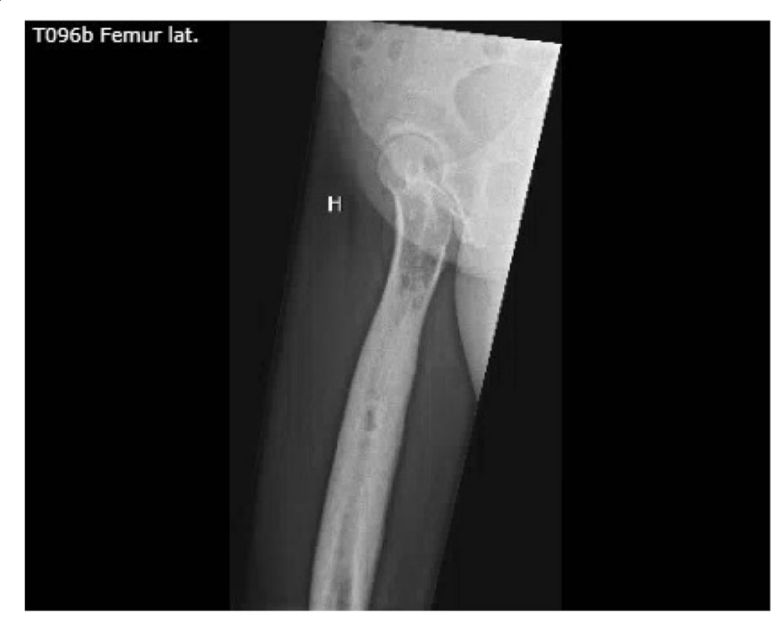

Fig. 3 X-ray right femoral shaft. $X$-ray of the patient's right femoral shaft showing irregular hyperostosis shorten the interval between administrations to further strengthen control of a hypermetabolic state. The second dose of $60 \mathrm{mg}$ was given after 8 weeks and this interval has been kept up to the present.

Biochemistry after treatment with both zoledronic acid and denosumab showed suppression of bone-type basic phosphatase, osteocalcin, collagen I, and procollagen I, with a relative increase in parathyroid hormone, and plasma ionized calcium within the normal range. The injections with denosumab were well tolerated with no adverse effects reported. During the whole treatment period, the injections were administered from our out-patient clinic without cancellations.

\section{Follow-up and outcomes}

After the first three doses given 8 weeks apart, there was pain remission for 8 months; in this period our patient did not take any orally administered analgesics. At the latest follow-up in February 2018, she complained of a slight increase in pain and occasional use of paracetamol and nonsteroidal anti-inflammatory drugs.

The treatment with denosumab was well tolerated with no side effects observed.

A $\mathrm{Tc}^{99}$-bone scan and computed tomography (CT) scan were performed in February 2017 and in February 2018, 5 and 17 months after the first injection with denosumab; the pathologically increased activity and cortical thickening were stationary.

\section{Discussion}

Melorheostosis occurs sporadically [4]. The disease tends to follow a sclerotomal distribution suggesting it originates in a segmentary embryogenetic defect [12]. This case report describes a case of monostotic sclerosing bone disease in an otherwise healthy young woman. The diagnosis of melorheostosis is based on the radiological findings of uneven hyperostosis of the proximal femur, also known as a flowing candlewax configuration.

Tentative diagnoses have been excluded by: thorough investigation of medical history; clinical, radiological, and biochemical examinations; genetic testing; as well as a biopsy of the affected bone. The bone biopsy was informative only in the sense that it helped exclude active inflammation, malignancy, and fibrous dysplasia. Melorheostosis has been associated with osteogenic sarcoma $[13,14]$ and malignant fibrous histiocytoma [15]. Histomorphometric evaluation of a bone biopsy measuring 1 $\mathrm{cm}^{3}$ showed no sign of malignancy.

In this case report, pain is the only symptom. In other studies of melorheostosis, pain has also been found to be the most prevalent symptom [3]. Melorheostosis can be monostotic or polyostotic and the lower limbs are most often affected $[3,16]$, in some cases causing a difference in limb length. Associated findings have been reported to be 


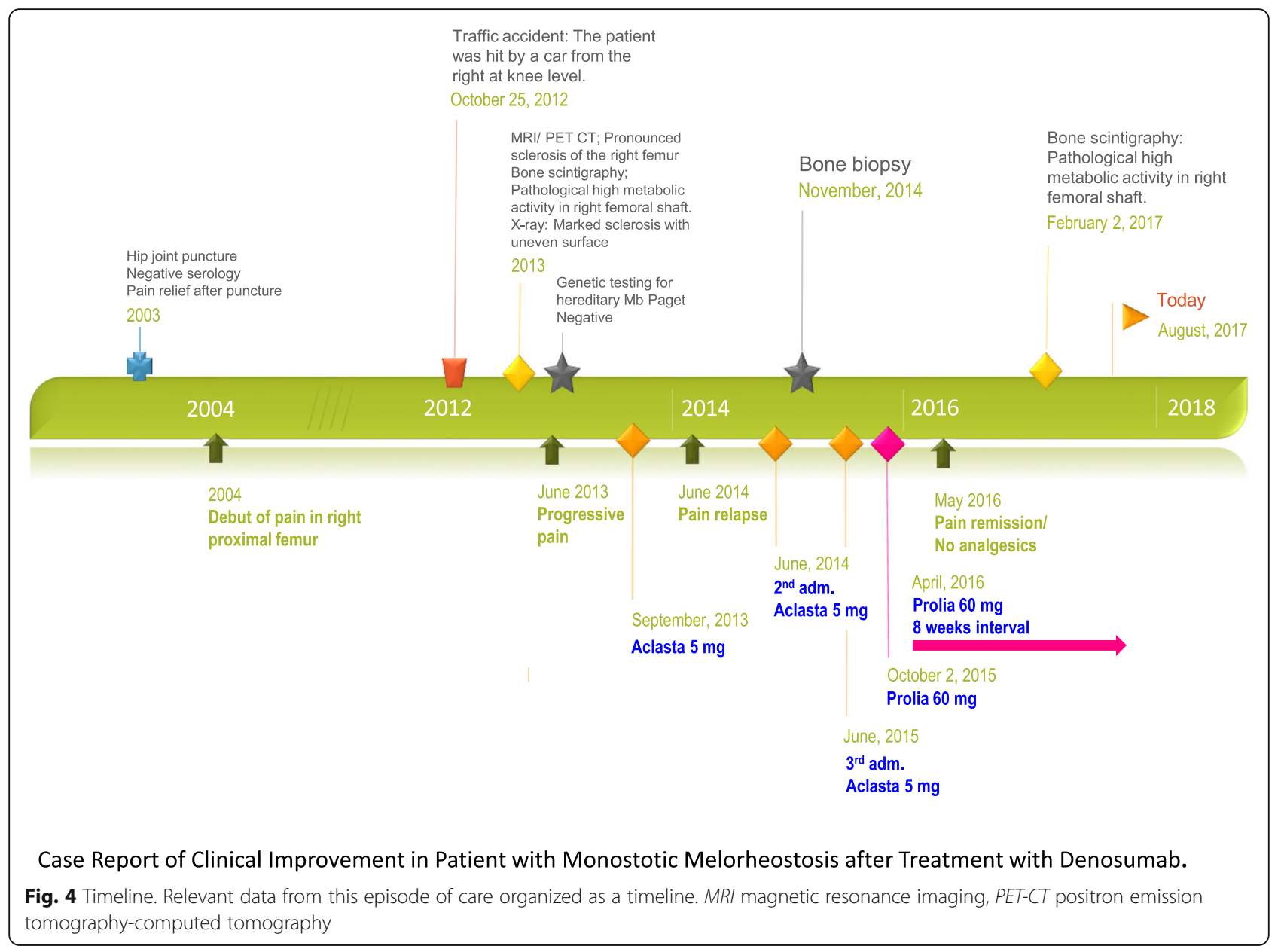

soft tissue fibrosis in the affected area [17], deformity, edema [11], and, rarely, vascular malformations [18]. These are reported in a minority of cases and in the current case there were no associated findings.

It has been speculated whether loss-of-function mutations in $L E M D 3$ could be central to the pathophysiology of melorheostosis; this mutation is usually not present in cases of sporadic melorheostosis [19]. One research group found that a number of genes coding for adhesion proteins were downregulated in melorheostosis-related skin lesions, with transforming growth factor- $\beta$ (TGF- $\beta$ )induced gene product ( $\beta$ ig-h3) being the most significantly affected [20].

In the medical literature, symptomatic relief has been achieved with orthopedic surgery, analgesics, physical therapy, and bisphosphonates [16]. This paper is the first to document that treatment with denosumab has a positive effect on disabling pain in a patient with melorheostosis. The attenuating effect of denosumab on biochemical markers of bone formation and on clinical symptoms has been shown to last approximately 2 months. This may help to shed light on the pathophysiology of a rare disease and points to a high bone turnover. Denosumab was more effective for long lasting pain relief than bisphosphonate in this case report; therefore, one can speculate whether the disease may be caused by local dysregulation in the RANK/ RANKL pathway.

A hypermetabolic state is also evident by the increased tracer uptake in a bone scan; this is consistent with findings in other reported cases of melorheostosis $[5,10]$.

Melorheostosis is a rare disease; it is heterogeneous in its presentation, leaving some uncertainty in establishing the diagnosis. However, among monostotic sclerosing bone diseases, the irregular cortical hyperostosis is specific for this condition.

In conclusion, this is the first report indicating that denosumab has a place in the treatment of melorheostosis when the effect of bisphosphonate treatment is insufficient.

\section{Conclusion}

The rationale for the conclusion

In this case of monostotic melorheostosis, there was a recurrence of disabling pain after one injection with 
Table 1 Biochemistry before and during treatment with zoledronic acid and denosumab

\begin{tabular}{|c|c|c|c|c|c|c|}
\hline & & Before treatment & $\begin{array}{l}\text { After treatment } \\
\text { Zoledronic acid }\end{array}$ & $\begin{array}{l}\text { After treatment } \\
\text { denosumab }\end{array}$ & $\begin{array}{l}\text { Treatment } \\
\text { denosumab }\end{array}$ & $\begin{array}{l}\text { Treatment } \\
\text { denosumab }\end{array}$ \\
\hline & & 3 Jul 2013 & 24 Sep 2013 & 28 Dec 2015 & 23 Mar 2016 & 03 Feb 2017 \\
\hline P-Calcium & $\mathrm{mmol} / \mathrm{L}$ & 2.27 & & 2.32 & 2.33 & 2.49 \\
\hline P-lonized calcium & $\mathrm{mmol} / \mathrm{L}$ & & & 1.22 & 1.2 & 1.23 \\
\hline P-Alkaline phosphatase & $U / L$ & 58 & & 43 & 33 & 42 \\
\hline P-Alkaline phosphatase, bone type & $U / L$ & & 5.6 & 7.2 & 6.2 & 7.1 \\
\hline P-Osteocalcin & $\mu \mathrm{g} / \mathrm{L}$ & & 6.5 & 9.2 & 7 & 5 \\
\hline P-Parathyrin (PTH) & $\mathrm{pmol} / \mathrm{L}$ & & & 5.23 & 6.15 & 8.8 \\
\hline P-25-hydroxy-vitamin D & $\mathrm{nmol} / \mathrm{L}$ & 207 & & 140 & & 98 \\
\hline$C T x$ & $\mathrm{pmol} / \mathrm{L}$ & & $<0.03$ & $<0.03$ & $<0.03$ & $<0.03$ \\
\hline PINP & $\mu g / L$ & & 12 & 15.6 & 11 & 11.4 \\
\hline \multicolumn{7}{|l|}{ Plasma (P) } \\
\hline & & & $\begin{array}{l}\text { Jun } 2015 \text { to } \\
\text { Oct } 2015\end{array}$ & $\begin{array}{l}\text { Oct } 2015 \text { to } \\
\text { Dec } 2015\end{array}$ & $\begin{array}{l}\text { Feb } 2015 \text { to } \\
\text { Mar } 2016\end{array}$ & \\
\hline Mean VAS score & & - & - & 4 & 4.3 & 4.5 \\
\hline Mean VAS (full year) & & 8 & 8 & 6 & 5 & 4 \\
\hline$\%$ days with pain killers & & & 23 & 36 & & 0 \\
\hline
\end{tabular}

PTH parathyroid hormone, VAS visual analog scale

zoledronic acid and lack of effect with repeated administrations.

To halter the increased bone turnover a more powerful anti-reabsorptive agent was chosen with the RANKL inhibitor denosumab. In this case, there was pain relief for 6 weeks after the first administration. At this time the pain intensity increased again, with a slight increase in bone markers. One could speculate if this was indicative of an underlying state of increased consumption of osteoprotegerin. It was decided to shorten the interval between administrations to 8 weeks resulting in continuous pain remission for the following 8 months. The stationary findings on bone scintigraphy after 1.5 years of treatment might be explained by the size of the affected area, and thus we expect decreased activity in future scans.

\section{The primary "take-away" lesson from this case report}

This is the first report indicating that denosumab has a place in the treatment of melorheostosis when the effect of bisphosphonate treatment is insufficient.

Availability of data and materials

All data generated or analyzed are included in this published article.

\section{Authors' contributions}

SB drafted the first manuscript supervised by PS. BA, MK, and SR did special analyses, evaluated the data, discussed the case with SB and PS, and finally suggested revision of the manuscript. SB and PS integrated changes proposed by the other authors and wrote the final version. All authors approved the final manuscript and submission for publication.

\section{Ethics approval and consent to participate}

The Danish Health Authority was informed of the off label use of denosumab as treatment in this case.

\section{Consent for publication}

Written informed consent was obtained from the patient for publication of this case report and any accompanying images. A copy of the written consent is available for review by the Editor-in-Chief of this journal.

\section{Competing interests}

The authors declare that they have no competing interests.

\section{Publisher's Note}

Springer Nature remains neutral with regard to jurisdictional claims in published maps and institutional affiliations.

\section{Author details}

${ }^{1}$ Department of Endocrinology, Copenhagen University Hospital Rigshospitalet, Blegdamsvej 9, 2100 Copenhagen, Denmark. ²Department of Medicine, Holbæk Hospital, Denmark and OPEN, Institute of Clinical Research, University of Southern Denmark, Odense, Denmark. ${ }^{3}$ Department of Endocrinology and Metabolism, Odense University Hospital, Odense, Denmark. ${ }^{4}$ Rheumatology and Bone Diseases Unit, Western General Hospital, University of Edinburgh, Edinburgh, UK.

Received: 16 March 2018 Accepted: 28 August 2018 Published online: 27 September 2018

\section{References}

1. Leri A, Joanny J. Une affection non décrite des os hyperostose "en coulée" sur toute la longeur d'un member ou "melorhéostose". Bull Mem Soc Med Hosp Paris. 1922:46:1141-5.

2. Wynne-Davies R, Gormley J. The prevalence of skeletal dysplasias. An estimate of their minimum frequency and the number of patients requiring orthopedic care. J Bone Jt Surg Br. 1985;67-B(1):133-7.

3. Freyschmidt J. Melorheostosis: a review of 23 cases. Eur Radiol. 2001;11(3):474-9.

4. Faruqi T, Dhawan N, Bahl J, Gupta V, Vohra S, Tu K, et al. Molecular, phenotypic aspects and therapeutic horizons of rare genetic bone disorders. Biomed Res Int. 2014;2014 https://doi.org/10.1155/2014/670842. 
5. Azouz EM, Greenspan A, Scientifique E, Cormier-Daire V. Melorheostosis. 2005. Available from: https://www.orpha.net/data/patho/GB/uk-Melorheostosis. pdf. Accessed 11 Mar 2018.

6. Hollick RJ, Black A, Reid D. Melorheostosis and its treatment with intravenous zoledronic acid. BMJ Case Rep. 2010;5 bcr0420091757bcr0420091757. Available from: http://casereports.bmj.com/cgi/doi/10.1136/ bcr.04.2009.1757. Accessed 11 Mar 2018.

7. Vyskocil V, Koudela K, Pavelka T, Stajdlova K, Suchy D. Incidentally diagnosed melorheostosis of upper limb: case report. BMC Musculoskelet Disord. 2015;16:2.

8. Saadallaoui Ben Hamida K, Ksontini I, Rahali H, Mourali S, Fejraoui N, Bouhaouala $\mathrm{H}$, et al. Atypical form of melorheostosis improved by pamidronate. Tunis Med. 2009;87(3):204-6. Available from: http://www.ncbi. nlm.nih.gov/pubmed/19537015. Accessed 11 Mar 2018.

9. Bied JC, Malsh C, Meunier P. [Melorheostosis in adults. Apropos of 2 cases, 1 of them treated with diphosphonate (EHDP)]. Rev Rhum Mal Osteoartic. 1976 43(3):193-199. Available from: http://www.ncbi.nlm.nih.gov/pubmed/ 817388. Accessed 11 Mar 2018.

10. Slimani S, Nezzar A, Makhloufi H. Successful treatment of pain in melorheostosis with zoledronate, with improvement on bone scintigraphy. BMJ Case Rep. 2013; https://doi.org/10.1136/bcr-2013-009820.

11. Donáth J, Poór G, Kiss C, Fornet B, Genant H. Atypical form of active melorheostosis and its treatment with bisphosphonate. Skelet Radiol. 2002; 31(12):709-13

12. Murray RO, McCredie J. Melorheostosis and the sclerotomes: a radiological correlation. Skelet Radiol. 1979;4(2):57-71.

13. Brennan DD, Bruzzi JF, Thakore H, O'Keane JC, Eustace S. Osteosarcoma arising in a femur with melorheostosis and osteopathia striata. Skelet Radiol. 2002;31(8):471-4.

14. Böstman OM, Holmström T, Riska EB. Osteosarcoma arising in a melorheostotic femur. A case report. J Bone Joint Surg Am. 1987;69(8): 1232-7. Available from: http://www.ncbi.nlm.nih.gov/pubmed/3478336

15. Baer SC, Ayala AG, Ro JY, Yasko AW, Raymond AK, Edeiken J. Case report 843. Malignant fibrous histiocytoma of the femur arising in melorheostosis. Skeletal Radiol. 1994;23(4):310-4. Available from: http:/www.ncbi.nlm.nih. gov/pubmed/8059261

16. Smith GC, Pingree MJ, Freeman LA, Matsumoto JM, Howe BM, Kannas SN, et al. Melorheostosis: A Retrospective Clinical Analysis of 24 Patients at the Mayo Clinic. Pm\&R. 2016;9(3):283-288. Available from: https://doi.org/10. 1016/.j.pmri.2016.07.530.

17. Soffa DJ, Sire DJ, Dodson JH. Melorheostosis with linear sclerodermatous skin changes. Radiology. 1975;114(3):577-8.

18. Kalbermatten NT, Vock P, Rüfenacht D, Anderson SE. Progressive melorheostosis in the peripheral and axial skeleton with associated vascular malformations: imaging findings over three decades. Skeletal Radiol. 2001; 30(1):48-52. Available from: https://www.ncbi.nlm.nih.gov/pubmed/ 11289635

19. Hellemans J, Debeer P, Wright $M$, Janecke A, Kjaer KW, PCM V, et al. Germline LEMD3 mutations are rare in sporadic patients with isolated melorheostosis. Hum Mutat. 2006;27(3):290. Available from: http://www.ncbi. nlm.nih.gov/pubmed/16470551

20. Kim JE, Kim EH, Han EH, Park RW, Park IH, Jun SH, et al. A TGF- $\beta$-inducible cell adhesion molecule, $\beta$ ig-h3, is downregulated in melorheostosis and involved in osteogenesis. J Cell Biochem. 2000;77(2):169-78.

Ready to submit your research? Choose BMC and benefit from:

- fast, convenient online submission

- thorough peer review by experienced researchers in your field

- rapid publication on acceptance

- support for research data, including large and complex data types

- gold Open Access which fosters wider collaboration and increased citations

- maximum visibility for your research: over $100 \mathrm{M}$ website views per year

At BMC, research is always in progress.

Learn more biomedcentral.com/submissions 